Bryn Mawr College

Scholarship, Research, and Creative Work at Bryn Mawr

College

Psychology Faculty Research and Scholarship

Psychology

1998

\title{
Phonetic Skills and Vocabulary Size in Late Talkers: Concurrent and Predictive Relationships
}

Jennifer Mirak

Leslie Rescorla

Bryn Mawr College, lrescorl@brynmawr.edu

Let us know how access to this document benefits you.

Follow this and additional works at: http://repository.brynmawr.edu/psych_pubs

Part of the Psychology Commons

\section{Custom Citation}

Mirak, Jennifer, and Leslie Rescorla. "Phonetic Skills and Vocabulary Size in Late Talkers: Concurrent and Predictive Relationships." Applied Psycholinguistics 19 (1998): 1-17, doi: 10.1017/S0142716400010559.

This paper is posted at Scholarship, Research, and Creative Work at Bryn Mawr College. http://repository.brynmawr.edu/psych_pubs/11

For more information, please contact repository@brynmawr.edu. 


\title{
Phonetic skills and vocabulary size in late talkers: Concurrent and predictive relationships
}

\author{
JENNIFER MIRAK and LESLIE RESCORLA \\ Bryn Mawr Collegc
}

\author{
ADDRESS FOR CORRESPONDENCE \\ Jennifer Mirak, Department of Psychology, Bryn Mawr College, 101 N. Merion Avenue, Bryn \\ Mawr, PA 19101. Email: jmirak@brynmawr.edu
}

\begin{abstract}
Phonetic skills and vocabulary size were investigated in 37 toddlers (24 to 31 months) identified with specific expressive language impairment and 20 comparison toddlers matched on age, SES, and nonverbal ability. The use of consonants was highly consistent across two contexts: 20 minutes of structured testing and 5 minutes of free play. The comparison children produced almost triple the number of consonant types and five times as many consonant tokens as the late talkers. However, the most frequently present consonants were similar across groups, indicating delayed rather than deviant phonetic development in the late talkers. The late talkers used a much higher proportion of their consonants in initial position than did the normally developing toddlers. Consonant types and tokens were significantly related to reported vocabulary size on Rescorla's (1989) Language Development Survey. No significant predictive relationship was found between either phonetic repertoire or vocabulary size at intake and age 3 language outcome. However, age $3 \mathrm{MLU}$ and IPSyn scores were significantly predicted by age-normed severity of expressive delay at intake (Reynell Expressive $z$ score), with more delayed children showing poorer outcomes.
\end{abstract}

Delayed expressive language is a common problem in preschool children and is associated with later leaming difficulties (Bishop \& Adams, 1990; Catta, Hu, Larivee, \& Swank, 1994) and behavioral and adjustment problems (Beitchman, Hood, \& Inglis, 1990; Cantwell \& Baker, 1987; Richman, Stevenson, \& Graham, 1982; Silva, McGee, \& Williams, 1983). A commonly used language milestone for normal development is a minimum 50-word vocabulary and the use of some word combinations at 24 months (Rescorla, 1989). With the Language Development Survey (LDS), Rescorla (1989) and Rescorla, Hadicke-Wiley, and Escarce (1993) found that 10 to $19 \%$ of middle-class 2-year-olds failed to reach criterion on one or both of these language measures. Research by Rescorla (1993) and Paul and Alforde (1993) suggested that 50\% of toddlers with an expressive language delay will continue to demonstrate expressive language deficits at age 3 (Whitehurst \& Fischel, 1994).

Two-year-olds who are slow to talk have reduced vocabulary size and delayed onset of word combinations. In addition to their lexical and syntactic delays, 
language-delayed toddlers have also been found to differ from normally developing toddlers in phonological development (Paul \& Jennings, 1992; StoelGammon, 1991). In her retrospective analysis of early speech ( 9 to 24 months), Stoel-Gammon (1989) found observable differences in phonetic development between two late-talking toddlers and normally developing children. The first late talker's prespeech utterances were marked by an absence of consonant sounds, while the second late talker's babbling reflected unusual sound preferences. At 24 months, both of these children demonstrated limited phonetic inventories as well as simpler productions with respect to syllable shape.

In normally developing 2-year-olds, Stoel-Gammon (1989) found a link between phonetic inventory size and the size of the child's lexicon. Such evidence lends support to the notion that a synchronous relationship exists between the developing phonological and lexical systems in normal 2-year-olds. Children with relatively few sounds have rather small vocabularies, while children with more complete phonetic repertoires have larger vocabularies. This is probably a bidirectional effect: limited phonetic skills constrain vocabulary acquisition, but a small expressive vocabulary may be associated with limited verbalization and, therefore, reduced opportunities for vocal practice (Locke, 1994).

Building on the work by Stoel-Gammon (1989), Paul studied phonetic repertoire using a larger sample of late talkers. Specifically, Paul and Jennings (1992) compared the phonological behavior of a group of 28 late talkers with that of a group of 25 age-matched controls (18 to 34 months). A comparison of the consonant inventories showed that the children identified as language-delayed produced significantly fewer consonant sounds during a 10-minute speech sample than did their normally developing agemates. On the other hand, the phones that appeared in the limited inventories of the delayed children were those that typically appear early on in the normal development of a child's phonological system. In addition, Paul and Jennings (1992) found that the late talkers' productions included a greater proportion of simpler syllable shapes than did those of the comparison children, who demonstrated a use of advanced syllable types. This evidence supports the idea that the phonetic development of the late talker is delayed but not deviant relative to the normal pattem of speech development.

A study by Thal, Oroz, and McCaw (1995) examined the phonological and lexical development in a group of 17 toddlers (18 to 30 months of age), all of whom scored in the lowest 10 th percentile for vocabulary by matemal report on the MacArthur Communicative Development Inventory: Toddlers (CDI) (Fenson et al., 1993). Ten of the late talkers produced at least 10 different words in a 30-minute speech sample (the meaningful speech group, or MSG), while seven (the premeaningful speech group, or PSG) did not. Although the MSG toddlers had somewhat larger reported CDI vocabularies, this difference was not significant. The MSG children were as voluble as the age- and language-matched controls, whereas the PSG toddlers produced fewer vocalizations, whether intelligible or unintelligible, than the children in either comparison group. Whereas the MSG late talkers were not significantly different from the age-matched controls in the number of consonants produced in word-initial position or in maturity of syllable shape, the PSG late talkers differed on both these measures from their same-age peers. In addition, the initial consonants present in more than $50 \%$ of 
the phonetic inventories were highly similar for MSG late talkers and agematched controls, whereas no initial phones were produced by $50 \%$ of the PSG children. MSG late talkers produced more final consonants than PSG late talkers, but both subgroups were significantly different from age-matched controls in final consonant use, confirming that both severely and mildly delayed late talkers differ from age-matched controls on the more advanced phonetic skill of final consonant use.

Rescorla and Ratner (1996) examined the speech productions of a subset of the late talker sample used in the current study. They studied the children's rate of vocalization, phonetic inventory size, and syllable shapes used during a 10minute free-play session with their mothers. When compared with their normally developing agemates, the late talkers demonstrated less vocalization, a limited consonantal inventory, and a predominant use of single vowel sounds and $\mathrm{CV}$ units in their speech productions.

The link between phonetic inventory and lexicon size at 24 months has been established in normally developing toddlers (Stoel-Gammon, 1989). The study by Thal and colleagues (1995) suggested that reported vocabulary size and phonetic inventory size are somewhat related in late talkers, although this was not directly investigated. It seems reasonable to predict, however, that vocabulary size and phonetic repertoire might be linked to some degree in late talkers, as late talkers appear to represent the extreme end of the normal spectrum in both lexical and phonological development. That is, they have smaller vocabularies and smaller phonetic inventories than their normally developing peers (Paul \& Jennings, 1992; Rescorla \& Ratner, 1996), but are similar both lexically and phonetically to language-matched younger toddlers (Thal et al., 1995).

Although existing studies have indicated that toddlers with expressive language delay vary widely in language outcome at age 3 , few reliable predictors of this differential outcome have been found. Whitehurst and his colleagues (Whitehurst, Smith, Fischel, Amold, \& Lonigan, 1991) found that the proportion of consonantal to vowel babble at age 2 predicted individual differences in expressive language scores at a 5-month follow-up. Preliminary analyses from the current longitudinal study (Rescorla, 1993; Rescorla \& Schwartz, 1990) indicated that the best predictors of language outcome at 3 were age and degree of expressive lag at intake: that is, the closer the child was to 31 months of age and the more delayed his or her language was at intake, the more likely he or she was to have a poor outcome at 3. However, phonetic repertoire was not analyzed in that study, and the sample did not include the full longitudinal cohort. Thus, a question addressed by the present study is whether 24-31-month phonetic repertoire and/or vocabulary size have predictive validity for language outcome at age 3.

In summary, the current study investigated the relation between phonetic repertoire and vocabulary size in a sample of late-talking toddlers at age 2 , as well as the predictive relation between these intake variables and language outcome at age 3. Unlike Rescorla and Ratner (1996), the study employed virtually the full sample of late talkers participating in Rescorla's longitudinal study of late talkers. This sample of late talkers is unique because all of the children were between 24 and 31 months of age at intake and all had normal receptive lan- 
guage skills. Another difference from Rescorla and Ratner (1996) is that we examined phonetic repertoire in two contexts: mother-child free-play sessions (5 minutes) and testing with the Bayley Scale of Infant Development (Bayley, 1969) and the Reynell Developmental Language Scales (Reynell, 1977) (20 minutes). For both contexts, group comparisons of number of different consonants produced (types), total number of consonants produced (tokens), consonantal inventory composition, and distribution of consonant use across position were carried out. Then phonetic characteristics were compared with vocabulary size at intake for both groups. Finally, the predictive validity of intake phonetic and lexical skill for language outcome at age 3 was examined for the late talkers.

\section{METHOD}

\section{Subjects}

A total of 57 children between the ages of 24 and 31 months were assessed: 37 children (33 boys, 4 girls) with specific expressive language impairment in Rescorla's (Rescorla \& Schwartz, 1990) longitudinal cohort (i.e., all late talkers in the sample with full videotape data at intake) and 20 toddlers (all boys) randomly drawn from the comparison cohort of 39 normally developing children, matched for age, SES, and nonverbal ability with the late talkers. Late talkers were obtained through advertisements placed in local newspapers as well as through notices sent to pediatricians requesting normally developing toddlers with little or no expressive language. Both groups were seen for the administration of the Bayley Scales of Infant Development (Bayley, 1969) and the Reynell Developmental Language Scales (Reynell, 1977). Additionally, each child was referred for audiological screening and was evaluated for social-emotional status by a clinical psychologist. Normal neurological status was established based on medical histories.

Specific expressive language impairment was identified by the following criteria: Bayley Mental Development Index (MDI) above 85; Reynell Receptive Language Age within 3 months of chronological age (CA); Reynell Expressive Language Age of 6 months or more below CA; and no evidence of emotional or behavioral disturbance, neurological impairment, or significant hearing loss. Criteria for inclusion in the comparison group were identical with the exception that their Reynell Expressive Language Age had to be within 3 months of CA.

All subjects in the study met these intake criteria with the exception of three late talkers who had Reynell Receptive ages of 4 months below CA age and one comparison child who had a Reynell Expressive age of 4 months below CA. However, because these deviations from the selection criteria were minor and no differences in the results were found when these subjects were eliminated from the analyses, they were retained for all analyses.

Demographic and psychometric data show that the two groups were very similar in terms of age and Hollingshead SES scores (see Table 1). The two groups were equivalent in terms of nonverbal cognitive ability, as indicated by comparable scores above the basal level on the 19 nonverbal Bayley items. Although their receptive language skills were at age level, the late talkers scored significantly below the comparison toddlers in Reynell Receptive language $z$ 
Table 1. Intake and outcome measures for late talkers and comparison children

\begin{tabular}{|c|c|c|}
\hline & Late talkers & $\begin{array}{c}\text { Comparison } \\
\text { children }\end{array}$ \\
\hline Intake age & $26.42(2.38)$ & $26.25(2.09)$ \\
\hline Hollingshead total & $53.82(12.59)$ & $56.68(10.12)$ \\
\hline Bayley Nonverbal items & $13.83(3.05)$ & $14.90(2.99)$ \\
\hline Reynell Receptive $z$ score & $.14(0.55)^{*}$ & $.82 \quad(.74)$ \\
\hline Reynell Expressive $z$ score & $-1.70(.45)^{*}$ & $.25 \quad(.55)$ \\
\hline LDS vocabulary & $20.87(21.63)^{*}$ & $235.42(69.05)$ \\
\hline Age $3 \mathrm{MLU} z$ score & $-1.62(1.51)^{*}$ & $1.19 \quad(.58)$ \\
\hline Age 3 IPSyn $z$ score & $-2.27(1.61)^{*}$ & $.50 \quad(.56)$ \\
\hline
\end{tabular}

Note: LDS = Language Development Survey (Rescorla, 1989).

${ }^{*} p<.001$, for independent group $t$ tests.

score. As would be expected, the late talkers showed significant delays on Reynell Expressive language $z$ score, performing more than 1.5 SDs below age expectations.

\section{Measures}

The primary data used in this study were the phonetic productions coded from a speech sample collected at intake. The procedure for collecting these data is described in the procedure section. In addition, several other language measures were analyzed.

Language Development Survey. Vocabulary size at intake (24 to 31 months of age) was assessed using the LDS (Rescorla, 1989), a vocabulary checklist completed by the mothers of the late talkers and those of the comparison group children. The LDS contains 310 of the most frequently used words in children's early vocabularies. The LDS has good concurrent validity with expressive vocabulary measures, and its sensitivity and specificity are high; for example, it can identify high proportions of delayed and normal toddlers with few false positives or false negatives. Test-retest reliability and internal consistency are also high, making the LDS a reliable, valid, sensitive, and specific tool for identifying expressive language delay (Rescorla, 1989).

Large differences in intake vocabulary as measured by the LDS were found between the late-talking toddlers and their comparison agemates (see Table 1). The mean number of words in the reported vocabularies of the late talkers was about 21 words, whereas the mean vocabulary size for the comparison group was 235 words. Only one late talker had a reported vocabulary of more than 50 words; this child had an intake LDS vocabulary size of 131 words, but he produced no word combinations.

Age 3 outcome measures. Language outcome at age 3 was assessed by MLU and IPSyn scores based on a 100-utterance speech sample collected during 30 
minutes of free play with the mother using the Fisher-Price Village. After transcription according to the CHILDES system (MacWhinney, 1991) and the exclusion of unintelligible utterances, imitations, immediate self-repetitions, and yes/no replies to questions, MLU in morphemes was calculated using the CLAN program (MacWhinney, 1991) on a 100-utterance corpus. In addition, each 100utterance corpus was scored on the IPSyn (Scarborough, 1990), which measures syntactic and morphological development in the areas of noun phrase, verb phrase, question/negation, and sentence structure. For three of the late talkers, a 30-minute play session did not yield 100 intelligible utterances; therefore, IPSyn $z$ scores were calculated based on either 75 (one child) or 50 utterances (two children), using Scarborough's (1990) prorated means and standard deviations.

Late talkers as a group were significantly delayed in expressive language skills, as measured by MLU and IPSyn at age 3, relative to their comparison peers (see Table 1). On average, the late talkers were 1.6 SDs below age expectations in MLU and more than $2 S D$ s below age in IPSyn score.

\section{Procedure}

Speech sample collection. Subjects were videotaped during the intake administration of the Bayley Scales of Infant Development and the Reynell Receptive and Expressive Language Scales. Mother-child free-play sessions were also videorecorded in the testing room; for two children, the father was the play partner. The pair was given a standard basket of toys including dolls, blocks, trucks, and accessories and was asked to play as freely as they would at home. Free-play sessions were recorded for approximately 10 minutes or until the child refused to play.

Coding. Phonetic coding was done for 10 minutes of the Bayley administration, 10 minutes of the Reynell administration, and 5 minutes of the free-play session. In coding the speech samples from the standardized test sessions, the same subtests were coded for each of the children. Expressive language items on each of the test measures were included in an effort to get a sample with the greatest amount of verbal production.

For both free-play and test data, intelligible and unintelligible utterances were coded for consonants in the initial, middle, or final position. The consonants that were coded included semivowels $(/ j, w /)$, fricatives $\left(/ f, \theta, s, \int, v, \delta, z, 3\right)$, nasals $(/ \mathrm{m}, \mathrm{n}, \mathrm{g} /)$, stops $(/ \mathrm{p}, \mathrm{t}, \mathrm{k}, \mathrm{t}, \mathrm{b}, \mathrm{d}, \mathrm{g}, \mathrm{d} 3 /)$, and liquids $(/ \mathrm{r}, \mathrm{l} /)$. The following rules were used in coding:

1. If the utterance was unintelligible, each syllable was coded individually, with the initial consonant coded as initial and the final consonant as final (e.g., "badagak," "ba" = initial $b$, "da" = initial $\alpha$, "gak" = initial $g$ and final $k$ ).

2. If the target word was apparent yet the production was inaccurate, the production was coded as uttered (e.g., "goggie" for doggie). 
3. Reduplicated syllables were coded individually (e.g., "dada" $=2$ initial $d s$, "gagaga" $=3$ initial $g s$ ) whether or not the word was intelligible.-

4. Words comprised of two words (e.g., dumptruck, bathtub) were coded as two words.

5. $W$ and $y$ were not coded in the final position.

6. Crashing or clicking sounds, yawns, and crying were not coded.

7. Contractions (e.g., can't) and words with a possessive $s$ (e.g., baby's bottle) were coded as one word.

Consonants used in each position were tallied for each child. If the child used a sound in a position three or more times, he or she was given credit for using that sound in that position. The number of different consonants used ("types") as well as the total number of consonants produced ("tokens") by each child were tallied using two different methods. Using the strict method, if a consonant was not produced at least three times in at least one position, it was not included as a type, nor was it counted in the total tokens for that child. Using the lenient method, any consonant used three times, regardless of position (e.g., once each in initial, middle, and final positions), was counted as a type and was included in the total tokens.

The mean number of types and tokens was calculated for each group using both the strict and the lenient methods. As would be expected, the lenient method produced slightly larger counts of both types and tokens, but it made no difference at all in the general pattern of results. To avoid redundancy, therefore, the results reported here derive only from the strict method of counting, unless otherwise specified. Data presented in the figures and tables are based on the strict counting method.

The primary coder (the first author) was not blind to subject membership in the late talker or the comparison group. This was unavoidable because the differences between groups were so profound that group membership was immediately apparent from viewing the tapes.

Reliability. A third of the total sample (13 late talkers, 6 comparison children) was used to determine interrater reliability. Phonetic coding of the free-play sessions was compared with coding of the same tapes done by speech pathology graduate students enrolled in a phonology seminar. For each child, the number of different consonant types used was compared. Interrater reliability was .94 for the entire sample. Interrater reliability was also very high for each group analyzed separately, where the range was somewhat more restricted: .87 for the late talkers and .87 for the comparison children.

Data analysis. Group differences on phonetic and lexical measures were examined using independent $t$ tests. We investigated relationships between the variables using Pearson correlations. The main issues addressed by this research were examined first using the two speech contexts separately. However, because the principal findings of the study were identical in both contexts, we decided 
to pool the data from the two contexts for the purposes of the main analyses reported here. The relationship between intake lexical and phonetic measures and age 3 language outcome scores was examined using regression analysis.

\section{RESULTS}

\section{Context comparisons}

Speech sample data collected during the mother-child free-play session ( $5 \mathrm{~min}$ utes) and the developmental testing ( 20 minutes) revealed highly consistent findings when analyzed separately. The correlation between number of consonant types used across the two contexts was .85. For tokens, the correlation was .71, which was also significant at the $p<.001$ level. There were significant correlations between types and tokens in both contexts (e.g., .87 for test context, .91 for free-play context, both $p<.001$ ), as well as significant correlations between phonetic repertoire in each context and reported vocabulary size (e.g., .87 for types in the test context, .86 for types in the free-play context, both $p<.001$ ). Finally, there were highly significant group differences in consonant types and tokens in both contexts, although the testing context, which was more than twice as long, resulted in about twice as many tokens for both groups. Group means for types were 4.74 versus 15.35 in the test context and 3.11 versus 11.40 in the free-play context; group means for tokens were 55.03 versus 304.80 in the test context and 26.60 versus 121.00 in the free-play context (for all, $p<.001$ ). In short, because no major differences between the contexts were found, the data were pooled across contexts to obtain a larger and hence more reliable corpus of utterances for each child and to make the presentation of the study results more efficient.

\section{Phonetic characteristics}

Figure 1 shows that the mean number of different consonants used (types) for the comparison group was $16.15(S D=2.23)$, almost three times that of the late talker group, which was $5.62(S D=3.38), t(53)=-14.11, p<.001$. Using the more lenient method of counting, the groups were also significantly different: mean types of 16.35 versus 6.30 .

As shown in Figure 2, the between-group difference in mean number of total consonant productions (tokens) was also significant, with the comparison group producing over five times as many as the late talker group. The mean for the comparison group was $424.70(S D=167.15)$, while for the late talker group it was $79.24(S D=64.96), t(22.15)=-8.89, p<.001$. The results using the more lenient method of counting were virtually identical: 425.70 versus 81.68 tokens.

The degree to which these two measures of phonological production were related was examined using Pearson correlations relating types and tokens in each group. A strong, highly significant positive correlation was found between number of types and number of tokens for the sample as a whole $(r=.86, p<$ $.001)$. That is, the children who used the fewest different consonants in their speech also produced the fewest consonant-containing utterances, while the chil- 


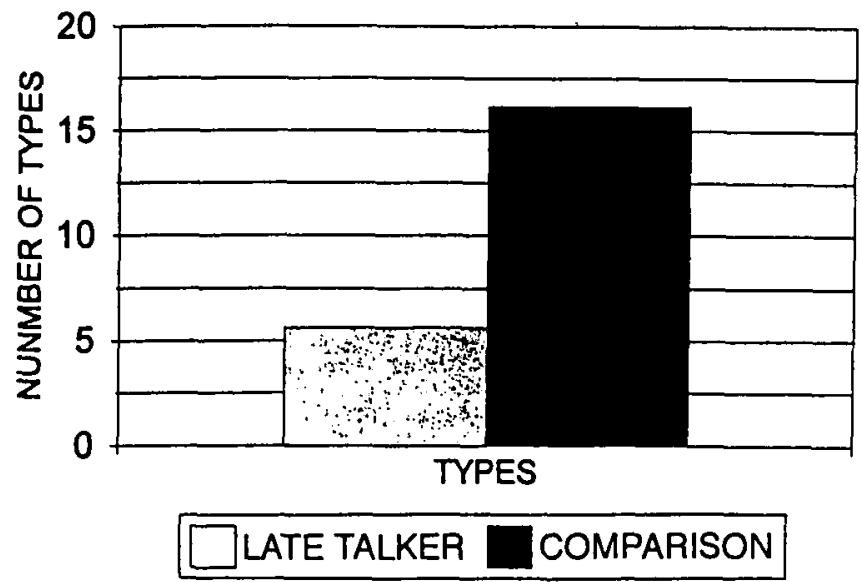

Figure 1. Total number of different consonants used: Mean types by group.

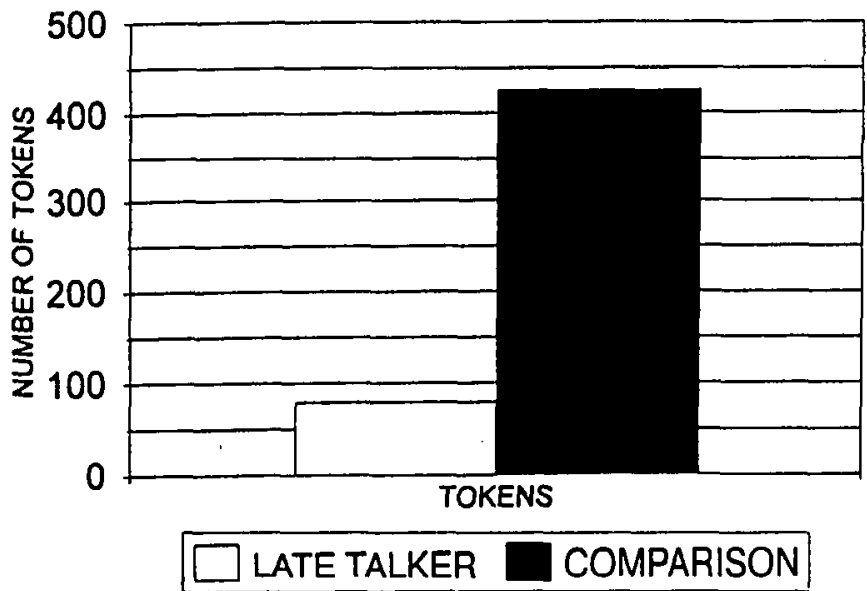

Figure 2. Total number of consonants produced: Mean tokens by group.

dren who produced more utterances with consonants also used a wider array of consonant sounds. This correlation between types and tokens was also highly significant for the late talker group, when analyzed separately $(r=.81, p<.001)$. In the comparison group, a positive correlation was found between types and tokens, but it was not significant $(r=.42$, n.s.), probably because there was relatively little variability in the number of consonant types in this group.

Although the comparison group used more consonant types than the late talker group, the content of the inventories was not qualitatively different: the inventories of the comparison children included all of the sounds used by the 
Table 2. Consonant use during speech samples: Percentages of children using types and tokens

\begin{tabular}{|c|c|c|c|c|}
\hline \multirow[b]{2}{*}{ Sounds } & \multicolumn{2}{|c|}{ Types (percentages) } & \multicolumn{2}{|c|}{ Tokens (numbers) } \\
\hline & Late talkers & $\begin{array}{c}\text { Comparison } \\
\text { children }\end{array}$ & Late talkers & $\begin{array}{c}\text { Comparison } \\
\text { children }\end{array}$ \\
\hline d & 73 & 100 & 528 & 1161 \\
\hline $\mathbf{n}$ & 60 & 100 & 239 & 912 \\
\hline $\mathrm{k}$ & 32 & 100 & 140 & 753 \\
\hline $\mathrm{b}$ & 68 & 100 & 453 & 727 \\
\hline $\mathrm{m}$ & 68 & 100 & 499 & 689 \\
\hline$r$ & 14 & 100 & 21 & 597 \\
\hline $\mathrm{f}$ & 32 & 100 & 108 & 503 \\
\hline $\mathrm{g}$ & 16 & 100 & 42 & 285 \\
\hline w & 46 & 95 & 112 & 439 \\
\hline$t$ & 30 & 90 & 136 & 676 \\
\hline $\mathrm{j}$ & 30 & 90 & 129 & 259 \\
\hline$s$ & 27 & 85 & 231 & 665 \\
\hline 2 & 11 & 85 & 15 & 270 \\
\hline f & 8 & 80 & 10 & 137 \\
\hline 1 & 3 & 65 & 5 & 146 \\
\hline j & 11 & 65 & 52 & 97 \\
\hline $\mathrm{v}$ & 5 & 50 & 10 & 64 \\
\hline th & 8 & 40 & 21 & 49 \\
\hline is & 8 & 25 & 69 & 27 \\
\hline$d$ & 5 & 15 & 10 & 9 \\
\hline$\theta$ & 3 & 15 & 3 & 13 \\
\hline$n$ & 0 & 10 & 0 & 14 \\
\hline 3 & 3 & 5 & 16 & 3 \\
\hline
\end{tabular}

late-talking children as well as additional consonants. Table 2 shows that, in the late talker group, all but one of the 23 sounds was represented, yet not one consonant sound was used by $100 \%$ of the group. Even when the more lenient method of counting was used, no consonant was used by $80 \%$ of the group. Four phones were included in at least $50 \%$ of the late talkers' inventories $(/ \mathrm{m}$, $\mathrm{n}, \mathrm{b}, \mathrm{d} /$ ), and an additional six phones $(/ \mathrm{j}, \mathrm{w}, \mathrm{s}, \mathrm{p}, \mathrm{t}, \mathrm{k} / \mathrm{)}$ were included in at least $25 \%$ of all late talker inventories. These numbers did not change when the lenient method of counting was used.

In terms of representation of the possible 23 consonant sounds in the children's speech sample inventories, the comparison group showed comprehensive phonological use: at least one child met the usage criterion of at least three uses in a single position for each of the 23 phones, and over $50 \%$ of the sample had 17 out of 23 phones in their inventories $\left(/ j, w, f, s, \int, v, z, m, n, p, t, k, b, d, g\right.$, $r, \mathrm{l} /$ ). The consonant sounds used most frequently were $/ m, n, p, k, b, d, g$, $\mathrm{r} /$, and these were found in $100 \%$ of the inventories; $/ \mathrm{j}, \mathrm{w}, \mathrm{t}, \mathrm{f}, \mathrm{s} /$ were used by $80 \%$ of the comparison children. Using the lenient counting method, four consonants that were already used by at least $65 \%$ of the children increased from 70 to $100 \%$ of the subjects. 
Considerable overlap was seen between the comparison and late talker inventories. As previously stated, the sounds used by the late-talking toddlers composed a subset of those included in the comparison inventories. Furthermore, within each group, the sounds had comparable relative frequencies. For example, all of the consonants used by at least $50 \%$ of the late talkers were included in the group used by $100 \%$ of the comparison children. Similarly, all of the consonants used by at least $25 \%$ of the late talkers were included in at least $80 \%$ of the comparison inventories.

As can be seen in Table 2, a qualitative comparison of the sounds produced most often (relative toker: use) revealed little difference between groups. In the late talker sample, the ten consonants produced the most frequently, in decreasing order of use, were $/ \mathrm{d}, \mathrm{m}, \mathrm{b}, \mathrm{n}, \mathrm{s}, \mathrm{w}, \mathrm{k}, \mathrm{t}, \mathrm{j}, \mathrm{p} /$. In the comparison group, the consonants used most frequently were $/ d, n, k, b, m, t, s, r, p, w /$. Nine of the most frequently used consonants were shared between the groups; the only differences were the inclusion of $/ \mathrm{j} /$ in the late talker group and $/ \mathrm{r} /$ in the comparison group. This finding supports the notion that the pattern of acquisition followed by the late talkers is delayed, yet quite similar to that of the normally developing children. That is, / $/$ / has consistently been reported as one of the early phones acquired, and $/ \mathrm{r} /$ typically appears later in children's inventories (Dyson, 1988; Stoel-Gammon \& Dunn, 1985).

Children's consonant use within utterances was analyzed using a 3 (position: initial, medial, and final) $\times 2$ (group: late talker and comparison) mixed-model analysis of variance. For the positional analyses, a consonant had to be used at least three times in a given position to be credited. Significant effects of group. $F(1,55)=124.81, p=.001$, and position, $F(2,100)=185.46, p=.001$, were found, revealing differences in the production of consonants in each position between the late talker and comparison groups, as well as differences between the use of consonants in the three positions in the groups as a whole. Post-hoc $t$ tests showed that consonant use in each position was greater in the comparison group than in the late talker group. However, although the comparison group produced more consonants in each of the three positions, the two groups were similar in that they each produced significantly more consonants in one orientation than another. Visual inspection revealed that in both groups initial consonant use was the greatest, followed by final and then medial use.

There was a significant status by position effect, $F(2,110)=62.58, p=.001$, indicating that consonant use differed significantly across the three positions as a function of group. As can be seen in Figure 3, initial consonant use was the greatest, followed by final and then medial use in both groups. However, a far greater proportion $(71 \%)$ of total consonant use by the late talker group occurred in initial position as compared with that by the normal group (58\%). Similarly, relatively fewer consonants were used by the late talker group in final position (20\%) than by the comparison group (30\%).

\section{Phonetic characteristics versus vocabulary size}

In order to investigate the relation between phonetic characteristics and vocabulary size, Pearson correlations were run between number of consonants used (types) and total number of consonants produced (tokens) (using the strict count- 

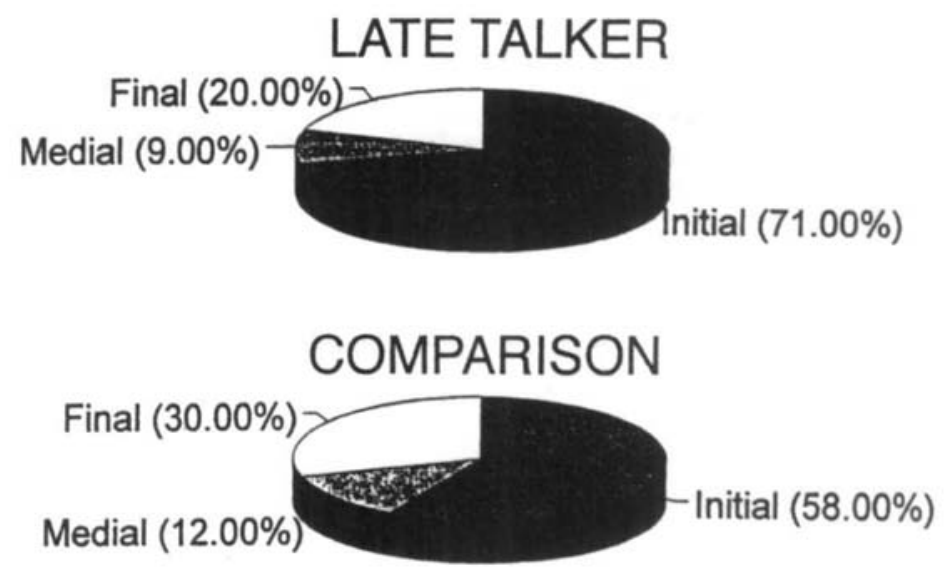

Figure 3. Token use by position: Distribution by group.

ing method) and intake vocabulary size, as reported on the LDS. Both phonetic types and phonetic tokens were highly correlated with vocabulary size at intake for the combined sample $(r=.86, p<.001$, for types, and $r=.88, p<.001$, for tokens). When only the comparison children $(N=19$; one child was missing the LDS) were analyzed, there were also strong relationships between intake vocabulary size and number and variety of phones produced $(r=.67, p<.01$, for types, and $r=.59, p<.01$, for tokens). When the late talkers were analyzed, phonetic token use had a significant relationship to intake vocabulary size $(r=$ $.33, p<.05)$, but the correlation for phonetic types was not significant $(r=.22$, n.s.). However, when the outlier with 131 words on the LDS (more than 6 SDs above the late talker mean) was removed from the sample, the correlation between phonetic types and vocabulary size became significant $(r=.41, p<.05)$, but the correlation for tokens was no longer significant $(r=.23$, n.s.).

Intake predictors of age 3 language outcome. For the late talkers, hierarchical multiple regression analyses were used to examine the relation between phonetic and lexical measures at intake and language outcome at age 3 in terms of MLU and IPSyn scores. For both regression analyses, number of phonetic types was entered first. As types and tokens were correlated at .81 for the late talkers, tokens were not used as an additional predictor. Next, total reported vocabulary size on the LDS was entered. The final predictor entered was the Reynell Expressive $z$ score, which reflects the child's expressive language status relative to age-based normative expectations. Other possible predictors (e.g., Bayley Nonverbal Ability score, Reynell Receptive Language $z$ score) were rejected because they were essentially uncorrelated with age 3 language outcome.

The size of the phonetic repertoire at intake explained virtually no variance in age 3 expressive language outcome (see Table 3). Similarly, the absolute size of the late talkers' vocabularies, as reported on the LDS, did not predict age 3 MLU to any appreciable degree. On the other hand, the degree of expressive 
Table 3. Regression analyses between intake and outcome measures

\begin{tabular}{|c|c|c|c|c|}
\hline Predictor & $R$ square & $\begin{array}{l}R \text { square } \\
\text { increase }\end{array}$ & $F$ & $p$ level \\
\hline \multicolumn{5}{|c|}{ Hierarchical regression predicting age $3 \mathrm{MLU}$} \\
\hline Phonetic types & .001 & .001 & .035 & .85 \\
\hline Intake LDS & .001 & .001 & .002 & .97 \\
\hline Reynell Exp z & .235 & .234 & 8.256 & .05 \\
\hline \multicolumn{5}{|c|}{ Hierarchical regression predicting age 3 IPSyn } \\
\hline Phonetic types & .000 & .000 & .000 & .99 \\
\hline Intake LDS & .014 & .014 & .392 & .54 \\
\hline Reynell Exp z & .351 & .338 & 14.050 & .001 \\
\hline
\end{tabular}

language delay as a function of CA (Reynell Expressive Language $z$ score) explained $24 \%$ of the variance in age $3 \mathrm{MLU}$, a significant increase in $R^{2}, F=$ $8.25, p<.01$.

A very similar pattem was found in the hierarchical regression using age 3 IPSyn as the dependent measure. Neither phonetic types nor intake LDS accounted for any variance in age 3 IPSyn. However, the Reynell Expressive Language $z$ score accounted for $35 \%$ of the variance in IPSyn $z$ score at age 3 , a highly significant increase in $R^{2}, F=14.05, p<.001$. Thus, the only significant predictor of age 3 language outcome was the degree of delay in expressive language at intake relative to age expectations.

\section{DISCUSSION}

The results of this study are consistent with those found in Paul and Jennings (1992), Thal et al. (1995), and Rescorla and Ratner (1996): children with delayed lexical acquisition were shown to have deficits in phonetic development. The two phonetic measures at intake, number of different consonants used (types) and number of total consonants produced (tokens) during a 25-minute speech sample, revealed significant differences between the late talkers and the normally developing toddlers. Comparison toddlers produced more consonant tokens as well as more consonant types.

For the late talker group, number of types and number of tokens used in the 25-minute speech sample showed a strong, significant correlation, while for the comparison group the correlation was positive but not significant. The lack of a significant finding in this case may have resulted from the fact that, although number of consonant types used ranged from 11 to 21,13 out of 20 children in the comparison group used between 16 and 18 different consonant types. In the late talker group, number of different types used ranged from 0 to 15 and showed a more evenly spread distribution across the $\mathbf{4 0}$ children.

The consonants used by at least $50 \%$ of the comparison group were $/ \mathrm{j}, \mathrm{w}, \mathrm{f}$, $s, \int, v, z, m, n, p, t, k, b, d, g, r, l /$, which is consistent with previous findings. The consonants used most frequently by the late talker group $-/ m, n, b, d /$ in $50 \%$ of the inventories and $/ \mathrm{j}, \mathrm{w}, \mathrm{s}, \mathrm{p}, \mathrm{t}, \mathrm{k} /$ in $25 \%$ - were similar to those $(/ \mathrm{b}$, 
$t, k, g, m, n, j, w, h /)$ noted in more than half of the inventories in Paul and Jennings's (1992) sample of 19 late-talking children, who ranged in age from 24 to 34 months. They were also comparable to those (/p, b, t, d, k, g, m, n, $?, \mathrm{~h} /$ produced in initial position by Thal et al.'s (1995) MSG late talkers.

Although the phonetic inventories of the late talkers were smaller than those of the comparison children, the patterns of acquisition were similar. Although no one consonant was produced by even $80 \%$ of the late talkers, those phones that were most widely represented in each group overlapped considerably. Similarly, the overall production of tokens was significantly less in the late talker group than in the comparison group, yet the consonant sounds that were produced the most times within each group were notably similar, with nine out of the ten most used consonants being shared.

An examination of the use of consonants across initial, medial, and final positions revealed, not surprisingly, that the comparison group produced more consonants in each of the three positions. Within both groups, differences were found between the use of consonants in each of the three positions, with initial use being greater than final use and final use being greater than medial use.

Among the comparison children, final consonant use (tokens) was just over half that of initial use (52\%), and consonant inventory size (types) in final position amounted to $58 \%$ of initial consonant inventory size. This is quite similar to the inventory size ratios found by Stoel-Gammon (1987) in her sample of 33 normally developing 24-month-olds and by Ingram (1981) in his sample of 15 children, aged 15 to 26 months. In contrast, our late talkers had final consonant tokens that totaled only $27 \%$ of initial consonant tokens, roughly half of that found in the normally developing children. A parallel analysis using consonant types indicated that late talkers had final consonant inventories that totaled only $37 \%$ of their initial consonant types. Thus, children in the late talker group used a much greater proportion of their total consonants in initial position and fewer consonants in final position than their normally developing peers. This general patterm is consistent with findings reported by Paul and Jennings (1992), Thal et al. (1995), and Rescorla and Ratner (1996). However, to our knowledge, actual initial-to-final consonant ratios were not explored in these other samples of late-talking toddlers.

Investigations of lexical development in normal and delayed populations have linked complexity of shape to vocabulary size, finding immature syllable shapes in toddlers with expressive language delay (Paul \& Jennings, 1992; Rescorla \& Ratner, 1996; Thal et al., 1995). For example, Paul and Jennings (1992) found that normally developing 2-year-olds produced many more VC syllables than their late-talking peers. The data presented here corroborate this finding, inasmuch as utterances with initial consonants predominated in the language output of our late talkers, while utterances with consonants in medial or final position were less frequent.

It is important to note that the method of phonetic coding used in the present study was biased against the recording of medial consonant use. In both groups, intelligible and unintelligible utterances were coded. In the case of unintelligible words, where the target word was not apparent, each syllable of the utterance 
was coded as a separate unit. This was done in order to avoid arbitrary decisions regarding the length of unintelligible strings. Thus, if a child produced a multisyllablic, but unintelligible target (e.g., "madoga"), the initial consonant of each syllable was coded as an initial sound (i.e., in this example, one $/ \mathrm{m} /$, one $/ \mathrm{d}$, and one /g/). However, if the utterance was intelligible as a word (e.g., banana), then the child would be credited with two medial consonants. The effect of this bias was likely to be more potent in the late talker sample, as their utterances were generally less intelligible.

The correlational analyses, which looked at the relationship between vocabulary size and phonetic skills for the combined sample and for the comparison group alone, indicated that children with smaller vocabularies had fewer sounds in their phonetic repertoires. The parallel analyses for the late talkers alone yielded a significant correlation for types after the child who was an intake vocabulary size outlier was excluded from the analysis. Thus, it appears that the number of consonant sounds a child has available affects, or is affected by, the overall amount of lexical production, with the direction of this relationship being unclear. Locke (1994) suggested that the late talker may have delayed neurological development, which allows the optimal period for language learning to pass before the early stages of acquisition of lexical forms begin. As a result, brain organization would be altered, and the child would continue to manifest restricted linguistic capacity. The potentially bidirectional nature of the forces involved in the slow development of expressive language was discussed by Rescorla and Ratner (1996). The underlying phonemic deficits may result in decreased vocalization, consequently reducing opportunities for children to be actively involved in verbal interactions and to gain the practice and reinforcement associated with language development.

One of the most surprising results of this study is that intake phonetic repertoire was not at all predictive of age 3 language outcome. Given that late talkers differed significantly from comparison children in both phonetic repertoire and vocabulary size and that there was a significant correlation between these two measures for the combined sample and for each group taken separately, it would seem plausible to assume that phonetic skill might be some kind of limiting factor in vocabulary acquisition. For example, it may be that the child with a broader range of sounds in his or her repertoire has the raw materials to construct a wider range of words and is likely to be more intelligible to listeners factors which should lead to faster vocabulary growth. However, this did not appear to be the case from our data. Some children with quite good phonetic skills were slow to acquire expressive language, whereas other children with very limited repertoires made good progress between the age of 2 and 3 .

It also seems quite counterintuitive that intake vocabulary size was not predictive of expressive language outcome six to twelve months later. However, on further reflection, this seems attributable to the fact that all of the children in the late talker group (with the exception of one outlier) had very small vocabularies. Apparently, variations in intake vocabulary size within the range of 1 to 50 words are less important in predicting language outcome than the severity of the delay relative to age expectations. Thus, a 20 -word vocabulary is a 
more significant and serious delay for a 30-month-old than for a 24-monthold, because children generally show rapid lexical progress between 24 and 30 months.

In sum, the late talkers who demonstrated the most rapid language acquisition by 36 months could not be identified at intake based on either their phonetic skills or their vocabulary size. However, the degree of expressive language delay relative to age expectations (e.g., Reynell Expressive Language $z$ score) did significantly predict age $3 \mathrm{MLU}$ and IPSyn. This finding is consistent with the finding in Rescorla and Schwartz (1990) - that both degree of expressive lag and intake age are correlated with language outcome in a negative direction. They found that the older the child is (between 24 and 31 months) when diagnosed as a late talker and/or the more delayed the child is relative to age expectations, the more likely it is that the child will continue to be delayed. Perhaps the children who showed less substantial expressive lags at intake were latebloomers who, by age 3 , had begun to catch up to the normally developing toddler. In contrast, the children who had delayed language at age $21 / 2$ and were thus diagnosed as late talkers, or those who had the most profound delays and greatest lags when diagnosed at intake, were the most likely to demonstrate delayed expressive language at age 3.

The results presented here suggest several implications for practitioners. First, toddlers with small vocabularies are very likely to present with limited phonetic repertoires and reduced volubility. Second, late talkers can be expected to have particular difficulty with final and medial consonants relative to initial consonant use. It is also clear from this research, as well as from previous studies, that toddlers who are slow to talk have delayed but not deviant phonetic skills. Thus, sounds that are easy to make for normally developing children are those most likely to appear in the repertoires of late talkers and therefore are the best candidates to be remediation targets. Finally, this research suggests that a child who presents with a vocabulary of fewer than 50 words and a limited phonetic repertoire at 30 months is at greater risk for continuing language delay than a child with exactly the same language skills at 24 months. Whereas parents of a 24-month-old late talker might do well to take a wait and see attitude, if the same child has not progressed by 30 months of age, aggressive intervention is probably recommended.

\section{ACKNOWLEDGMENTS}

This research was supported by grants to the second author from the Bryn Mawr College Faculty Research Fund and from the National Institute of Health (NICHD AREA Grant 1-R15-HD22355 and NIDCD R01-DC00807). Portions of this article were presented at the Biennial Meeting of the Society of Research in Child Development, March 1995, and at the Annual Conference of the American Speech and Hearing Association, December 1995. The authors wish to thank the children and parents who gave so generously of their time to participate in this research.

\section{REFERENCES}

Bayley, N. (1969). Bayley Scales of Infant Development. New York: Academic.

Beitchman, J. H., Hood, J., \& Inglis, A. (1990). Psychiatric risk in children with speech and language disorders. Joumal of Abnormal Child Psychiatry, 18, 283-296. 
Mirak \& Rescorla: Phonetic skills

Bishop, D. V. M., \& Adams, C. (1990). A prospective study of the relationship between specific language impairment, phonological disorders, and reading retardation. Journal of Child Psychology and Psychiatry, 31, 1027-1050.

Cantwell, D., \& Baker, L. (1987). Developmental speech and language disorders. New York: Guilford.

Catts, H. C., Hu, C.-F., Larivee, L., \& Swank, L. (1994). Eariy identification of reading disabilities in children with speech-language impairment. In R. V. Watkins \& M. L. Rice (Eds.), Specific language impairments in children: Current directions in research and intervention. Baltimore, MD: Brookes Publishing.

Dyson, A. (1988). Phonetic inventories of 2- and 3-year-old children. Journal of Speech and Hearing Disorders, 53, 89-93.

Fenson, L., Dale, P., Reznick, S., Thal, D., Hartung, J., Pethick, P., \& Reilly, J. (1993). The MacArthur Communicative Development Inventories. San Diegó, CA: Singular Press.

Ingram, D. (1981). Procedures for the phonological analysis of children's language. Austin, TX: Pro-Ed.

Locke, J. (1994). Gradual emergence of developmental language disorders. Journal of Speech and Hearing Research, 37, 608-616.

MacWhinney, B. (1991). The CHILDES Project: Tools for analyzing talk. Hillsdale, NJ: Erlbaum.

Paul, R., \& Alforde, S. (1993). Grammatical morpheme acquisition in 4-year-olds with normal, impaired and late-developing language. Journal of Speech and Hearing Research, 36, 12711275.

Paul, R., \& Jennings, P. (1992). Phonological behavior in toddlers with slow expressive language development. Journal of Speech and Hearing Research, 35, 99-107.

Rescorla, L. (1989). The Language Development Survey: A screening tool for delayed language in toddlers. Journal of Speech and Hearing Disorders, 54, 587-599.

(1993, March). Outcome of toddlers with specific expressive language delay (SELD) at ages 3 , 4, 5, 6, 7 \& 8. Paper presented at the Biennial Meeting of Society for Research in Child Development, New Orleans, LA.

Rescorla, L., Hadicke-Wiley, M., \& Escarce, E. (1993). Epidemiological investigation of expressive language delay at age two. First Language, 13, 5-22.

Rescorla, L., \& Ratner, N. (1996). Phonetic profiles of toddlers with specific expressive language impairment (SLI-E). Journal of Speech and Hearing Research, 39, 153-165.

Rescorla, L., \& Schwartz, E. (1990). Outcome of toddlers with expressive language delay. Applied Psycholinguistics, 11, 393-407.

Reynell, J. (1977). Reynell Developmental Language Scales-(Revised). Los Angeles: Western Psychological Corporation.

Richman, N., Stevenson, J., \& Graham, P. (1982). Preschool to school: A behavioral study. New York: Academic.

Scarborough, H. S. (1990). Index of Productive Syntax. Applied Psycholinguistics, 11, 1-22.

Silva, P. A., McGee, R., \& Williams, S. M. (1983). Developmental language delay from three to seven and its significance for low intelligence and reading difficulties at seven. Developmental Medicine and Child Neurology, 25, 783-793.

Stoel-Gammon, C. (1987). The phonological skills of two-year-olds. Language, Speech and Hearing Services in Schools, 18, 323-329.

(1989). Prespeech and early speech development in two late talkers. First Language, 9, 207, 224.

(1991). Normal and disordered phonology in two-year-olds. Topics in Language Disorders, 1/(4). 21-32.

Stoel-Gammon, C., \& Dunn, C. (1985). Normal and disordered phonology in children. Austin, TX: Pro-Ed.

Thal, D. J., Oroz, M., \& McCaw, V. (1995). Phonological and lexical development in normal and late-talking toddlers. Applied Psycholinguistics, 16, 407-424.

Whitehurst, G. J., \& Fischel, J. E. (1994). Early developmental language delay: What, if anything, should the clinical do about it? Journal of Child Psychology and Psychiatry, 35, 613-648.

Whitehurst, G. J., Smith, M., Fischel, J. E., Arnold, D. S., \& Lonigan, C. J. (1991). The continuity of babble and speech in children with specific expressive language delay. Journal of Speech and Hearing Research, 34, 1121-1129. 